Impact of Ice Nucleation

Parameterizations on CAM5 Simulated Arctic Clouds and Radiation: A Sensitivity Study

S. Xie, X. Liu, C. Zhao, Y. Zhang

February 5, 2013

19th International Conference on Nucleation and Atmospheric Aerosols

Fort Collins, CO, United States

June 23, 2013 through June 28, 2013 
This document was prepared as an account of work sponsored by an agency of the United States government. Neither the United States government nor Lawrence Livermore National Security, LLC, nor any of their employees makes any warranty, expressed or implied, or assumes any legal liability or responsibility for the accuracy, completeness, or usefulness of any information, apparatus, product, or process disclosed, or represents that its use would not infringe privately owned rights. Reference herein to any specific commercial product, process, or service by trade name, trademark, manufacturer, or otherwise does not necessarily constitute or imply its endorsement, recommendation, or favoring by the United States government or Lawrence Livermore National Security, LLC. The views and opinions of authors expressed herein do not necessarily state or reflect those of the United States government or Lawrence Livermore National Security, LLC, and shall not be used for advertising or product endorsement purposes. 


\title{
Impact of Ice Nucleation Parameterizations on CAM5 Simulated Arctic Clouds and Radiation: A Sensitivity Study
}

\author{
Shaocheng Xie ${ }^{a}$, Xiaohong Liu ${ }^{b}$, Chuanfeng Zhao ${ }^{a}$, and Yuying Zhang ${ }^{a}$ \\ ${ }^{a}$ Lawrence Livermore National Laboratory, Livermore, California, USA \\ ${ }^{b}$ Pacific Northwest National Laboratory, Richland, Washington, USA
}

\begin{abstract}
Sensitivity of Arctic clouds and radiation in the Community Atmospheric Model version 5 (CAM5) to ice nucleation parameterizations is examined. The physical reasons behind these changes in cloud amount and cloud microphysical properties are discussed. Model simulations of clouds and radiation are evaluated with available observations.
\end{abstract}

Keywords: ice nucleation; community atmospheric model (CAM); arctic clouds and radiation. PACS: $42.68 . \mathrm{Ge}, 92.70 . \mathrm{Np}, * 92.60 . \mathrm{N}-$, 92.60.Nv.

\section{INTRODUCTION}

The ice nucleation process has a large impact on model-simulated Arctic clouds. The presence of IN can largely influence ice growth and the complex interaction between the ice and liquid phases of cloud condensate, which in turn affects the radiative properties and lifetime of cold clouds. In this study, we examined two different ice nucleation schemes with Community Atmospheric Model version 5 (CAM5). One is the scheme developed by Meyers et al. (1992) [1], in which the ice number concentration is parameterized as a function of ice supersaturation without considering its spatial and temporal variations with respect to aerosol properties. This is the default scheme used in CAM5. Another one is the more physically based scheme described in DeMott et al. (2010) [2], which links the variation of ice number concentration to aerosol (dust) particles larger than 0.5 microns in diameter in addition to the dependency of temperature. The goal of this study is to better understand the important role of ice nucleation processes in clouds and radiation simulated by climate models with an emphasis on the Arctic region.

CAM5 with its finite volume dynamic core at the resolution of $0.90 \times 1.250$ in the horizontal is used in this study. Two 11-year "free-running" simulations of CAM5, one with the default scheme (CAM5O, hereafter) and the other one with the new ice nucleation scheme (CAM5DM, hereafter), are conducted with sea surface temperature (SST) and sea ice prescribed from the observations, and with the COSP simulators turned on in the simulations. The last 10 year data for these two runs are analyzed. Results are compared between the models and between the models and available observations. 


\section{RESULTS}

The new ice nucleation scheme results in a significant reduction of IN number concentrations in mixed-phase clouds (Fig. 1). The IN number concentrations in CAM5DM are up to 2 orders of the magnitude smaller than those predicted by CAM5O at all latitudes. This in turn leads to considerable changes in liquid water path (LWP) and ice water path (IWP) simulated with these two schemes particularly in high latitudes and the midlatitude storm track regions (Fig. 2). Over these regions, the smaller IN concentrations simulated by CAM5DM result in an increase $\left(>10 \mathrm{~g} \mathrm{~m}^{-2}\right)$ of LWP and a decrease $\left(>3 \mathrm{~g} \mathrm{~m}^{-2}\right)$ of IWP. This has been shown to be caused by the slow-down of the Bergeron-Findeisen process in mixed-phase clouds which results in a smaller conversion rate from cloud liquid to cloud ice/snow.

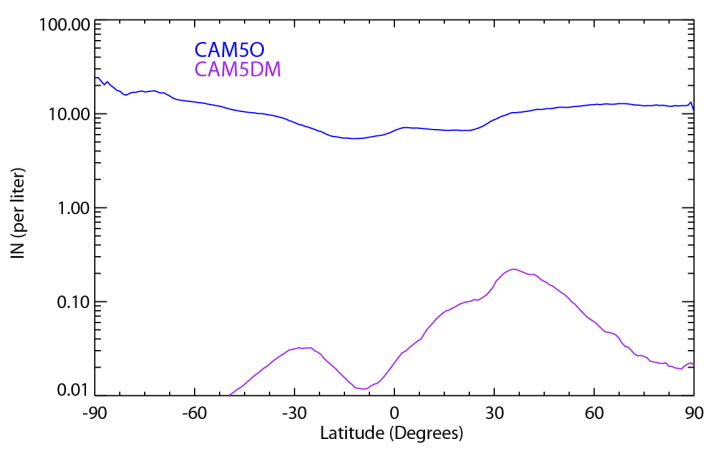

FIGURE 1. Vertically integrated Zonal and annual mean of the IN concentrations in mixed-phase clouds simulated by (a) CAM5O and (b) CAM5DM. (a line plot)
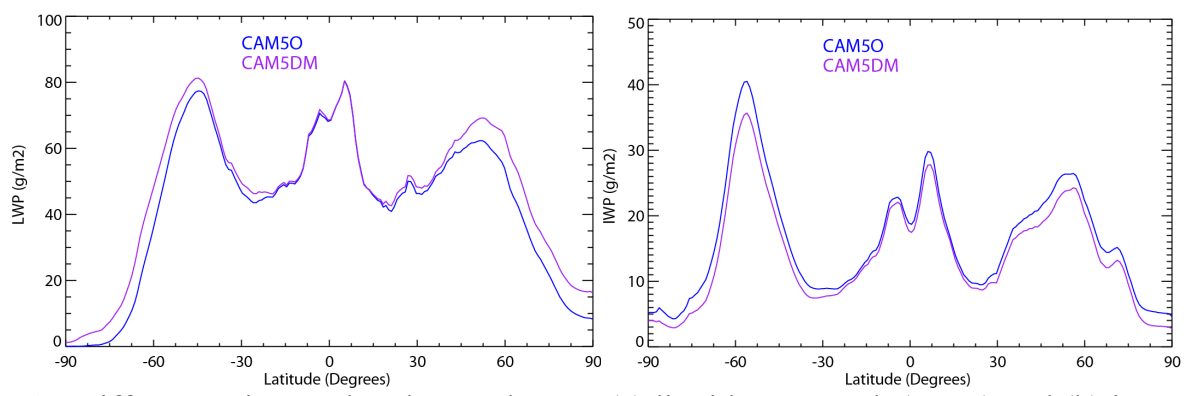

FIGURE 2. Differences in zonal and annual mean (a) liquid water path (LWP) and (b) ice water path

(IWP) between CAM5DM and CAM5O. (a line plot)

Similar to LWP and IWP, the largest impact on cloud amount is also in high latitudes and midlatitude storm tracks, where there is a significant increase in midlevel clouds (Figure 3a) and a large decrease in low-level clouds (Figure 3b) with the use of the new ice nucleation scheme. Changes in high clouds are moderate with a general increase of cloud amount seen over most regions. As a result, the changes in total clouds are relatively small. Further analysis shows that the changes in cloud amount are due to the complex interaction among the cloud macrophysics, microphysics, and the large-scale environment. 

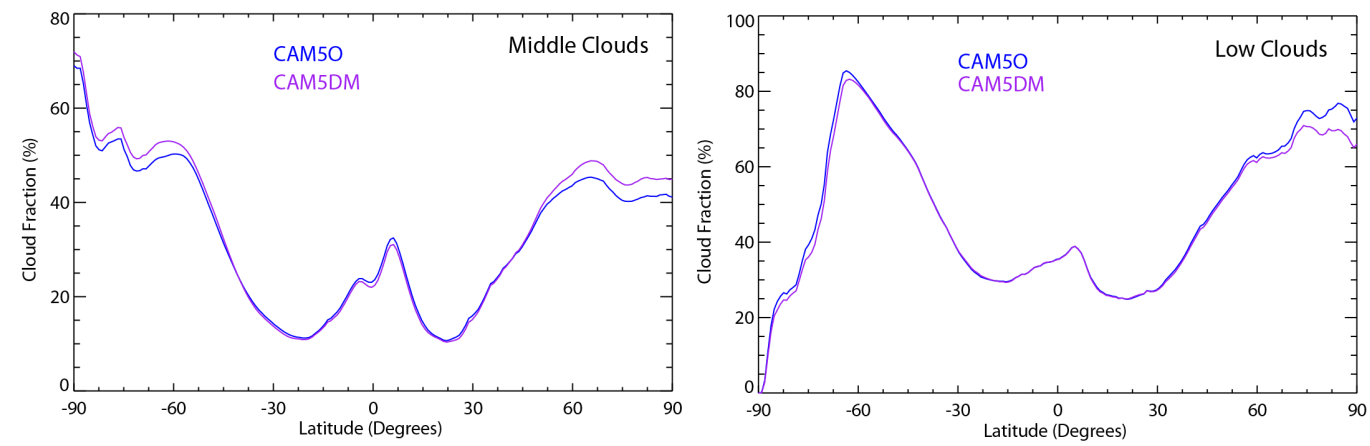

FIGURE 3. Differences in zonal and annual mean middle and low clouds between CAM5DM and CAM5O.

The preceding results indicate that Arctic clouds have the largest sensitivity to ice nucleation parameterizations and therefore we will emphasize our analysis on the Arctic region $\left(60^{\circ} \mathrm{N}-80^{\circ} \mathrm{N}\right)$ in the following discussion. The data used to compare with model simulations include clouds measured from the International Satellite Cloud Climatology Project (ISCCP) and radiation fluxes from the Clouds and the Earth's Radiant Energy System (CERES) observations and the Earth Radiation Budget Experiment (ERBE).

TABLE 1. The cloud frequency for the nine ISCCP cloud types in ISCCP and the ISCCP simulator in CAM5DM and CAM5O. The high, middle, and low-top clouds are defined as those with cloud top pressure less than $440 \mathrm{hPa}$, between $680 \mathrm{hPa}-440$ $\mathrm{hPa}$, and larger than $680 \mathrm{hPa}$, respectively. The optically thin, intermediate, and thick clouds are defined as those with the cloud optical depth in the range of 0.02-3.6, 3.623 , and larger than 23 , respectively.

\begin{tabular}{l|llll}
\hline Height & Thickness & ISCCP & CAM5O & CAM5DM \\
\hline High & thin & 1.25 & 1.85 & 1.95 \\
& Intermediate & 2.55 & 2.63 & 2.49 \\
Med & thick & 9.43 & 4.80 & 4.26 \\
& thin & 5.44 & 5.76 & 7.50 \\
& intermediate & 11.81 & 11.13 & 14.39 \\
Low & thick & 12.12 & 9.25 & 10.13 \\
& thin & 6.47 & 3.86 & 4.02 \\
& intermediate & 13.15 & 15.55 & 16.20 \\
& thick & 7.30 & 10.09 & 8.94 \\
\hline
\end{tabular}

Consistent with earlier discussions, lower IN concentrations in CAM5DM lead to a clear increase in middle-top clouds, particularly for optically intermediate and thick clouds where there is a roughly $30-40 \%$ increase compared to those produced by CAM5O (Table 1). For high- and low-top clouds, however, the results are mixed. CAM5DM generates fewer optically thin and intermediate high clouds and optically thin low clouds while it simulates more optically thick high clouds and optically intermediate and thick low clouds. Overall, the smaller IN concentrations in CAM5DM result in an increase of cloud optical depth $(\tau)$ of Arctic clouds and therefore clouds are much brighter than those in CAM5O. This results in a stronger 
LW, SW, and net cloud radiative forcing (cooling) at TOA in CAM5SM. The differences are about $1.4 \mathrm{~W} \mathrm{~m}^{-2}$ and $-3.9 \mathrm{~W} \mathrm{~m}^{-2}$ for the $\mathrm{LW}$ and $\mathrm{SW} \mathrm{CRF}$, respectively, which results in $-2.5 \mathrm{~W} \mathrm{~m}^{-2}$ in net CRF cooling (Table 2).

TABLE 2. Cloud radiative forcing (CRF) at the top of the atmosphere (TOA). Data are averaged between March and September over the Arctic region $(60 \mathrm{~N}-80 \mathrm{~N})$.

\begin{tabular}{l|lllll}
\hline & ERBE & CERES & CAM5O & CAM5DM & CAM5DM-CAM5O \\
\hline LW CRF & 19.32 & 18.99 & 16.04 & 17.38 & 1.34 \\
SW CRF & -53.97 & -47.21 & -48.38 & -52.21 & -3.83 \\
NET CRF & -34.65 & -28.22 & -32.34 & -34.83 & -2.49 \\
\hline
\end{tabular}

\section{SUMMARY}

Sensitivity of CAM5 simulated Arctic clouds and radiation to the ice nucleation process is examined by testing a new physically based ice nucleation scheme that links the variation of ice nuclei (IN) number concentration to aerosol properties. The new scheme leads to a significant reduction in simulated IN number concentrations at all latitudes while changes in cloud amount and cloud properties are mainly seen in high latitudes and middle latitude storm tracks. In the Arctic, there is a considerable increase in mid-level clouds and a decrease in low clouds. The smaller IN concentrations result in an increase of liquid water path and a decrease of ice water path. Overall, there is an increase of the optical depth of Arctic clouds, which leads to a stronger cloud radiative forcing (net cooling) at the top of the atmosphere. This suggests that the new IN scheme would produce less warming in its simulated Arctic climate than the default scheme.

\section{ACKNOWLEDGMENTS}

The contributions of S. Xie, C. Zhao, and Y. Zhang to this work were performed under the auspices of the U. S. Department of Energy (DOE), Office of Science, Office of Biological and Environmental Research by Lawrence Livermore National Laboratory under contract No. DE-AC52-07NA27344 and supported by the DOE Earth System Modeling Program and Atmospheric Radiation Measurement Program. Support for X. Liu was provided by the DOE Office of Science Atmospheric System Research (ASR) Program and Earth System Modeling Program. The Pacific Northwest National Laboratory is operated for the DOE by Battelle Memorial Institute under contract DE-AC06-76RLO 1830.

\section{REFERENCES}

1. M. P. Meyers and W. R. Cotton, J. Appl. Meteorol., 31, 708-721 (1992).

2. P. J. DeMott et al., Proc. Natl. Acad. Sci. (USA), 107, 11217-11222 (2010). 